\title{
Urgences
}

\section{Écrivant ce texte...}

\section{Madeleine Gagnon}

Numéro 10, 2e trimestre 1984

Spécial fantasmes

URI : https://id.erudit.org/iderudit/025151ar

DOI : https://doi.org/10.7202/025151ar

Aller au sommaire du numéro

Éditeur(s)

Urgences

ISSN

0226-9554 (imprimé)

1927-3924 (numérique)

Découvrir la revue

Citer cet article

Gagnon, M. (1984). Écrivant ce texte... Urgences, (10), 17-20.

https://doi.org/10.7202/025151ar

Ce document est protégé par la loi sur le droit d'auteur. L'utilisation des services d'Érudit (y compris la reproduction) est assujettie à sa politique d'utilisation que vous pouvez consulter en ligne.

https://apropos.erudit.org/fr/usagers/politique-dutilisation/
Cet article est diffusé et préservé par Érudit.

Érudit est un consortium interuniversitaire sans but lucratif composé de l’Université de Montréal, l'Université Laval et l'Université du Québec à Montréal. Il a pour mission la promotion et la valorisation de la recherche. https://www.erudit.org/fr/ 
MADELEINE GAGNON 
Écrivant ce texte, j'hésite entre théorisation et création, entre pensée du fantasme et production d'un scénario, qu'elle que soit SA fiction, puisque comme tout le monde, j'en Al, je possède secrètement pour moi toute-SEULE des dizaines d'histoires fabuleuses qui meublent mon imagination, qui la nourrissent, qui l'agrémentent, au gré des heures, des activités, des événements, des ans. J'aimerais écrire le TEXTE parfait, celui qui lierait (et qui lirait) dans une même trame les tissus conjonctifs d'une histoire fictive que je me fabrique littéralement de toutes pièces avec une écriture réflexive qui adhérerait fidèlement aux règles et aux jeux de ce récit, vu que le fantasme est à la fois ludique et laborieux, qu'il produit parallèlement du plaisir et du sens; ce TEXTE devient donc mon actuel fantasme: j'aimerais, dans une MÊME écriture, que s'épousent la jouissance et l'intelligence historique qu'apporte le fantasme.

Ce paragraphe est un concentré de tout ce que j'aimerais énoncer du fantasme, un noyau qui pourrait éclater dans tous les sens, mais comme seule m'intéresse l'écriture, je choisis de ne pas entrer dans les diverses élaborations conceptuelles des voies et ramifications de ce nucléus. J'opte aussi pour la pudeur d'écrire eu égard à la révélation brute d'un scénario de fantasme.

Mitoyenne, comme dit Claire Lejeune dans I'Atelier, je décide de poursuivre mon chemin d'écriture dans l'entre-deux du discours et de la fiction, dans l'antre peut-être, dans l'interstice, l'intermédiaire: dans la médiation ENTRE deux univers d'appartenance du fantasme, celui de l'Histoire dont il est une re-création singulière et celui de la Pulsion dont il est une Histoire particulière. Inter-médiation: rencontre, sur un même territoire psychique de I'Histoire arrogante de l'Autre avec les histoires les plus intimes du Soi. Rencontre amoureuse, non pas fusionnelle mais transférentielle, dans un MÊME sujet pourtant clivé, de deux territoires: celui de I'Autre et celui du Je.

Tout fantasme est né de l'absence de l'Autre quand le sujet soudain s'éprouve seul. 
Le fantasme est la conséquence d'une épreuve de solitude.

C'est parce que l'Autre s'en va, m'abandonne, que je l'invente, I'imagine OBJET de ma jouissance: Je le place au plus secret, au plus intime de ma jouissance pour conjurer les sorts de ma souffrance: celle de son départ, de sa disparition.

Je répète sans cesse le scénario de son apparition.

Face aux débris de la séparation, impuissante, je retrouve tous mes pouvoirs d'aimer en recréant à ma guise, à mon gré, à mon rythme tous les attributs de SA présence.

Sur le terrain vague du refoulé amoureux, quel que soit cet objet amoureux refoulé, je répète indéfiniment, inlassablement, I'heureux scénario de son retour éternel.

Pour les mêmes raisons graves liées à SON absence, je peux aussi sans cesse, et toujours dans une certaine jouissance, imaginer son éternel départ: fantasmer SA mort ou encore la mienne.

II est même possible que j'entre dans le fantasme de I'Autre me pleurant après ma propre mort: seul le fantasme possède ce don magique de me garantir l'Amour indéfectible et infini de l'Autre pour MOI.

Théâtre magique de la solitude, avec ses mises en scène invariables mais toujours perfectibles, ses rituels, ses cortèges d'images, de costumes, de déguisements; ses masques.

Fantasmagories de la vie intérieure en perpétuelle tentation de passage à l'Acte.

Spectacles silencieux avec ses paroles seules pour l'oreille du dedans.

Fantasme ultime: quand I'Autre du sujet s'imagine ail- 
leurs, sur une autre scène que Je, pour me faire jouir d'amour, MOI. 